\title{
Letter to Editor: Advancing age in medicine - bane or boon?
}

\author{
R. S. Rajan ${ }^{1}$
}

Received: 15 December 2020 /Revised: 23 December 2020 / Accepted: 30 December 2020 / Published online: 5 January 2022

(C) Indian Association of Cardiovascular-Thoracic Surgeons 2022

Dear Editor,

This is in response to your Editorial, "Advancing Age in Medicine- Bane or Boon" in the November-December 2020 issue of the Indian Journal of Thoracic and Cardiovascular Surgery [1].

The topic raises several important considerations. Starting with the animal kingdom, it is well-known that among many mammals and most primates, the alpha male (or alpha female as the case may be) is replaced by the next eligible candidate on death, disease, disability, or defeat of the incumbent.

Among humans, the arrangements are much more complex. Politicians never retire. In democracies, they are replaced when they lose an election, unless they have a "Trump" up their sleeve. In dictatorships, it is usually death, defeat in a war, or an internal or external coupnever a peaceful transition. Musicians and painters continue as long as they physically can, even up to their last days, unless a brighter, younger star appears on the horizon and sweeps them away to oblivion. Stage, TV, and film actors face a similar situation, unless they are extra-ordinarily talented and can hold the audience in their thrall, even in their old age, or change their roles to suit changed circumstances.

When it comes to doctors, general physicians and internists can pretty much continue in practice as long as health permits, though sometimes they have to live with the reality of a decline in number of patients.

Surgical specialties are more demanding. Mental and physical stamina, keen eyesight and hearing, quick reflexes, and critical decision making powers are sine qua non, even more so in specialties like neurosurgery and cardio-thoracic surgery.
Experience, trusted assistants, and a well-knit team can take away the strain to an extent, but the burden of responsibility remains. Is it worth it? This is a question which each surgeon has to answer himself or herself, like cricketers. How many of our senior surgeons will pass muster, if they are subjected to an Annual Medical Board to assess their fitness-like pilots? How many will make the grade, if their skills are tested by an impartial professional body as to their familiarity and skill with newer techniques and technology?

And is not it better to leave when people wonder why you have left, than wait until they wonder why you have not? And what is wrong in "the old order yielding place to new"? The new can and often does surpass the old. There is a time for every player to gracefully become coach, referee, manager, or even join the spectators and enjoy the unfolding spectacle, sans the burden of responsibility.

The topic remains controversial.

\section{Compliance with ethical standards}

Conflict of interest The author declares that there is no conflict of interest.

\section{Reference}

1. Yadava OP. Advancing age in medicine - bane or boon? Indian $\mathrm{J}$ Thorac Cardiovasc Surg. 2020;36:561-562.

Publisher's note Springer Nature remains neutral with regard to jurisdictional claims in published maps and institutional affiliations.
R. S. Rajan

drrsrajan@svym.org.in

1 Armed Forces Medical College, Pune, India 